\title{
Factors Affecting Students' Grades In Principles Of Economics
}

Orhan Kara, West Chester University, USA

Fathollah Bagheri, University of North Dakota, USA

Thomas Tolin, West Chester University, USA

\begin{abstract}
Factors affecting students' grades in principles of microeconomics and macroeconomics students are analyzed from the data collected in two public universities. Results indicate that gender, number of hours worked, SAT scores, number of missed classes, recommending the course to a friend, instructors, being a junior, number of economics courses taken, course, and interest in the course, were significant factors contributing to learning and success as measured by grades. Moreover, GPA, age, staying in university housing, number of mathematics classes taken, instructor's use of graphs to explain a topic, being a fourth year student, enrolling for a class because of the reputation of an instructor had positive effect on students grades, while the effect of the number of hours per week spent on studying for the class was negative.
\end{abstract}

\section{INTRODUCTION}

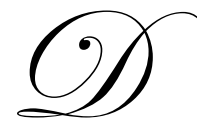

espite the programs to improve student learning of economics by organizations such as the National Council on Economic Education and the American Economics Association, we have just started to understand factors that affect student learning and performance in economics classes. Several studies investigate undergraduate economics teaching and learning by concentrating on backgrounds of students and personality type, the role and gender of instructor, student expectations, math skill, absenteeism, and so forth. However, there can be many other factors that have profound effect on learning and teaching principles of economics classes, such as the choice of textbook, choice of instructors, choice of class time, students' major, level of instructors' use of mathematics and a host of other class and students attributes that have not been addressed in the previous studies.

Therefore, this study investigates the impact of these factors as well as students and class attributes on learning in principles of economics classes. The paper proceeds with the literature review followed by an explanation of the data and methodology. Regression results are discussed in the next section followed by concluding remarks.

\section{LITERATURE REVIEW}

Studies investigating factors contributing to student performance and success in economics classes identify the following factors: gender, math skills, who is the instructor, teaching methods, absenteeism, class size, student effort, employment, seating location, and personality type.

The effect of gender is the most frequently studied factor in the literature, although research has not reached a definitive conclusion (Siegfried, 1979; Lumsden and Scott, 1987; Williams, Waldauer and Duggal, 1992; Borg and Stranahan, 2002; Ballard and Johnson, 2005). After a detailed analysis of the previous studies' findings, Siegfried (1979) is not able draw any strong conclusions, but he concludes that gender differences start developing during high school and extend to college years.

Following Siegfried's (1979) study, researchers try to understand and explain this difference. Lumsden and Scott (1985) argue that gender differentials might be explained by the type of exams students take in economics 
classes. Observing that the average male learning rate is higher than that of females, Lumsden and Scott (1985) also report that female students do better on essay exanimation, with an average of seven points more than male students. Male students average four points higher on multiple choice exams. Williams et al. (1992) does not find any evidence of gender differences in principles and upper level economics classes. Borg and Stranahan (2002), who look at race and personality type of each gender, and Ballard and Johnson (2005), who investigate the expectations of each gender, find evidence of gender differences.

Another factor of interest is the effect of mathematic skills on student performance in economics classes. Although a superior math skill is perceived as an advantage to understanding economics, the existing evidence is mixed. For example, Cohn, Cohn, Hult, Balch, and Bradley (1998) conclude that there is no significant effect of mathematics on understanding principles of economics. In an experimental study, Cohn and Cohn (2001), looking at the accuracy of drawing graphs and its effect on student performance, find that drawing accurate graphs helps students perform better. Extending the experiments into following semesters, Cohn, Cohn, Balch, and Bradley (2001) randomly place students into two sections of graph and no-graph lectures. The authors were not able to find any significant difference in the success of students.

The empirical effects of math skills on performance in economics classes remains mixed. Hill and Stegner (2003) report that students with a preference towards math performed better in principles of economics classes, especially on graphical questions. Cohn et al. (2004) examine the students' preferences towards graphs and reaches no definitive conclusion. And Ballard and Johnson (2004) do find a statistically significant effect of math skills on students' success. They assert that dexterity of basic algebra skills plays the most important role in introductory microeconomics class.

A third line of research focuses on who is the instructor and what are their teaching methods. Generally, there is a significant difference in the effect of instructors on student success and learning; there also are measurable effects due to introducing new ways of teaching with the advancement of technology (see Watts and Bosshardt, 1991; Vachris, 1999; Colander, 2005; and Goffe and Sosin, 2005).) Laband and Piette (1995) examine student performance in upper level economics classes by focusing on transfer students from community colleges. They conclude that students who take principles of economics classes at community colleges do worse than those who completed principles classes as the four year institution. The difference in the performance is attributed to differences between the instructors employed by the community colleges and the universities. While the effect of the instructor has a significant factor on student learning, the gender of instructors does not seem to make any difference in student performance (Robb and Robb, 1999).

Research examining attendance and absenteeism finds a strong positive correlation between student attendance and performance in economics classes (Durden and Ellis, 1995, Chan, Shum, and Wright, 1997; Marburger, 2001; and Cohn and Johnson, 2006). Using surveys collected from principles of microeconomics and macroeconomics classes, Durden and Ellis (1995) report significant positive effects of attendance on student success. Interestingly, missing up to four classes throughout the semester does not have any effect on student performance; attendance becomes a significant factor after four missed classes.

Since the impact of attendance is supported by most studies, the debate between researchers is whether there should be some type of penalty imposed on absenteeism and a requirement of mandatory attendance. Cohn and Johnson (2006) advocate mandatory attendance whereas Chan et al. (1997) argue against such a rule. Attendance may not be beneficial if the value added by instructors is low and/or if class size is large and studentinstructor interaction is low.

Class size is another variable of interest when predicting student success in economics classes. Earlier studies do not produce evidence of class size on student success (McConnell and Sosin, 1984), but recent studies do conclude that smaller classes are correlated with greater success (Aries and Walker, 2004). The debate on the effect of class size and learning does not seem to be settled.

With respect to the effect of student effort on performance, existing research also produces mixed results. For example, Borg, Mason, and Shapiro (1989) examine the relationship between the number of hours students 
spent on studying and students' grades. Dividing students into two groups based on their ACT or SAT scores, Borg et al. (1989) find an interesting pattern. The positive effect of student effort is significant in both groups, but the signs are confusing. Above average students receive higher grades as they spend more time on studying, but there is a negative correlation between time spent studying in principles of macroeconomics classes and the final grades for students in the below average group.

A number of studies report a negative but significant effect of student effort on performance (Didia and Hasnat, 1998; and Krohn and O'Connor, 2005), and Lumsden and Scott (1987) and Park and Kerr (1990) do not find any effect of student effort on student performance.

In addition to non-traditional students, who generally have full time jobs, traditional college students may also work, leaving less time available for their courses. Therefore, one might expect that having a job could reduce the success in economics classes. As expected, the literature confirms this fact. For example, Paul (1982) finds an inverse relationship between the number of hours worked and student grades. The estimated coefficient is relatively small, but statistically significant.

Other factors contributing to student learning include seating location and personality types. Benedict and Hoag (2004) find that students sitting in front seats in a classroom have higher probability of receiving A's; students who prefer rear seats have higher probability of receiving D's or F's. Usually seating location reflects the personality type of student and their preferences. Borg and Shapiro (1996), for example, study the personality types of students and performance in principles of economics classes. Overall, they report that when a student personality type is similar to the instructor's, as measured by Keirsey/Bates temperament scale, the student performs better in class.

In summary, many factors affect students' performance on economics classes. This study uses survey data to measure which factors contribute most to student learning in principles of economics classes. It differs from the previous papers in several ways. First, several new variables have been incorporated in the model that have been ignored in the previous studies. Second, the estimation method is the ordered logit, a method which is more appropriate for the letter grades as the dependent variable. Third, using the same sample survey, data are collected from two major universities in the Midwest and East coast resulting in a large sample size that would be more representative of the student population.

\section{DATA AND METHODOLOGY}

The data used in this study come from two sets of surveys administered at the University of North Dakota and West Chester University. At the University of North Dakota, the survey was given to students during the final exam in 2003 in order to increase the response rate. All the instructors of principles of economics classes (both micro and macro) agreed to give the survey to their students, and all the students who took the final exam filled out the questionnaires. The same survey was administered at West Chester University during the final exams in spring 2004. All instructors but one cooperated during the process. After collecting surveys, we also obtained the grades of the students who completed the survey. There are thirty eight questions in the survey and 744 responses are recorded.

In order to determine the effects of class characteristics and student attributes on learning economics, an ordered logit model is applied (Greene, 2002). Since the grades, our dependent variable, are ranked in order from the best to the worst (from A to F), we use the ordered logit model. We depart from Park and Kerr (1990) who use a multinomial logit approach. The following model is estimated by using Limdep software:

Grades $=\beta_{0}+\sum \beta_{\mathrm{i}}$ (class and student attributes) + error
$\mathrm{i}=1, \ldots, 34$

Grades are the final grades that students obtain, A, B, C, D, and F. Class and student attributes include GPA, gender, age, course, university housing, number of hours per week worked at a job, number of mathematics courses taken, number of economics courses taken, SAT score, expected grade at the beginning of the semester, 
expected grade at the end of the semester, number of hours per week spent studying for the class, number of missed classes, textbook rating by student, understanding when the instructor uses graphs to explain a topic, understanding when the instructor uses equations to explain a topic, interest in the course, whether to recommend the course to a friend, university, instructor (eight dummy variables for nine instructors), year of study (three dummy variable for sophomore, junior, and senior), and dummy variables for reasons for registering in the specific class

\section{RESULTS}

Sample characteristics are given in Table 1, summarizing the information about the 774 principles of microeconomics and macroeconomics students who were surveyed. $479(64.4 \%$.) students identify themselves as male and $265(35.6 \%)$ as female. The average grade is 2.64 out of 4 , a little below a B, and the average GPA is also around B (2.98). About $22 \%$ of the students received a grade of A, while $35 \%$ received B's, $31 \%$ C's, and the remaining $12 \%$ received D's and F's. Students are mainly first year students (39\%) and sophomores (about 40\%). Juniors and seniors constitute $21 \%$ of the sample.

Table 1: Descriptive Statistics

\begin{tabular}{|l|c|c|}
\hline \multicolumn{1}{|c|}{ Variables } & Mean & Std. Deviation \\
\hline Grade & 2.64 & 1.011 \\
\hline GPA & 2.98 & .567 \\
\hline Age & 19.83 & 2.515 \\
\hline Year in School : 1=Freshman 2=Sophomore 3=Junior 4=Senior & 1.86 & .850 \\
\hline \# of hours per week worked & 19.80 & 9.237 \\
\hline University housing: 1= Yes, 0=No & .57 & .495 \\
\hline Number of mathematics courses taken & 1.80 & 1.332 \\
\hline Number of Economics courses taken & 1.65 & 1.978 \\
\hline SAT Score & 1412.89 & 339.552 \\
\hline Expected Grade at the beginning of the semester & 2.32 & .994 \\
\hline Expected Grade at the end of the semester & 2.31 & .873 \\
\hline \# of hours per week spent on studying for the class & 2.79 & 2.143 \\
\hline Number of missed classes & 4.57 & 4.247 \\
\hline Textbook rating & 6.01 & 2.200 \\
\hline Understanding when the instructor uses graphs to explain a topic & 7.10 & 2.275 \\
\hline Understanding when the instructor uses equations to explain a topic & 7.17 & 2.202 \\
\hline Interest in the course & 5.71 & 2.345 \\
\hline Usefulness of the course & 6.26 & 2.273 \\
\hline Whether to recommend the course & .73 & .447 \\
\hline Preference: 1=50 minute class 0=75 minute class & .77 & .419 \\
\hline Preference: 1=Morning class 0= Afternoon class & .58 & .494 \\
\hline
\end{tabular}

More than half of the students maintain a job during the semester, working an average of twenty hours each week. The average age of students is twenty; $90 \%$ of the students are twenty-one years old or younger. In addition, $60 \%$ of the surveyed students are in the principles of microeconomics class and the remaining $40 \%$ are in macroeconomics class. $57 \%$ of the students surveyed live in university housing during the time the survey was administered.

Half of the students indicate that they had at least one math and one economics classes prior to taking the current class. Based on the student self reported SAT scores, the average was 1413 out of maximum 2400 combining math, critical thinking and writing, 800 each. WCU students had lower scores compared to the UND students. As Table 1 shows, the average expected grade changed very little from the beginning to the end of the semester. The adjustment in the expected grade took place in lower and higher end of the scale. While $25 \%$ of the students expected a grade of $\mathrm{D}$ in the beginning of the semester, $18 \%$ of students reported an expected grade of $\mathrm{D}$ at the end of the semester. Similarly, $13 \%$ of the students indicated an expected grade of A at the start of the semester, whereas $9 \%$ expected an A at the end of the course. On average, students spent less than three hours per week 
studying and missed an average of five classes throughout the semester. $62 \%$ of the students reported four or fewer missed classes.

On a scale of one to ten, one being very poor and ten being excellent, students rated the textbooks at about a six on a ten-point scale. Students indicate that they better understand when instructors use graphs and equations to explain a topic, with the ranks averaging 7.1 and 7.17 respectively. While the students' interest was about average in the class (the rank equals 5.71), the majority of the students (about 60\%) find the class useful and 73\% state that they would recommend the class to a friend.

With respect to registering for a specific class, $60 \%$ of the students state convenience, $24 \%$ percent report a conflict with other classes, $3 \%$ note a conflict with work, and 3\% note a conflict with personal affairs. $10 \%$ of the students cite the reputation of the instructor as a deciding factor when choosing a class. $77 \%$ of the students prefer a fifty-minute class to seventy-five minute class, and 58\% respond that morning classes are preferred to afternoon classes.

Results for correlations between grades and the independent variables are presented in Table 2. Positive, significant correlations exist between grades and the following variables: GPA, number of hours worked, number of economic courses taken previously, SAT scores, expected grade at the beginning of the semester, number of hours spent studying for the class, number of attended classes, instructors' use of graphs and equation, and interest in the course.

Table 2: Correlations with Grade

\begin{tabular}{|c|c|c|}
\hline & Correlation & Significance \\
\hline GPA & $0.60 * *$ & $(0.000)$ \\
\hline Gender 1=Female, $0=$ Male & 0.04 & $(0.253)$ \\
\hline Age & 0.03 & $(0.381)$ \\
\hline University housing: $1=\mathrm{Yes}, 0=\mathrm{No}$ & 0.03 & $(0.498)$ \\
\hline \# of hours per week worked at a job & $-0.11 *$ & $(0.021)$ \\
\hline Number of mathematics courses taken & 0.04 & $(0.232)$ \\
\hline Number of Economics courses taken & $0.10^{* *}$ & $(0.007)$ \\
\hline SAT Score & $0.23 * *$ & $(0.000)$ \\
\hline Expected Grade at the beginning of the semester & $-0.16^{* *}$ & $(0.000)$ \\
\hline Expected Grade at the end of the semester & 0.03 & $(0.496)$ \\
\hline \# of hours per week spent on studying for the class & $-0.09 *$ & $(0.023)$ \\
\hline Number of missed classes & $-0.22 * *$ & $(0.000)$ \\
\hline Textbook rating & 0.03 & $(0.477)$ \\
\hline Understanding when the instructor uses graphs to explain a topic & $0.29 * *$ & $(0.000)$ \\
\hline Understanding when the instructor uses equations to explain a topic & $0.24 * *$ & $(0.000)$ \\
\hline Interest in the course & $0.18^{* *}$ & $(0.000)$ \\
\hline
\end{tabular}

*. Correlation is significant at the 0.05 level (2-tailed)

**. Correlation is significant at the 0.01 level (2-tailed)

We estimate a negative correlation between grades and the number of hours per week spent studying. This result is puzzling, but it is consistent with some previous studies (Didia and Hasnat, 1998; Krohn and O'Connor, 2005). We discuss this result in the conclusion.

The ordered logit estimates for equation (1) are given in Table 3 and Table 4. According to the Table 3, the model is satisfactory as $\chi^{2}$ and log likelihood diagnostics are acceptable. The ordered logit method does not produce the familiar F-test, and a likelihood ratio test is conducted to examine the overall explanatory power of the model. The value of $\chi^{2}$ test statistic with thirty four degrees of freedom is 104.77 , implying that the model fits well and the independent variables are jointly significant. The $\mu$ 's, the cut off points for different grades, are all statistically significant. Dividing the estimated coefficient by the standard error does not give the usual t-statistics, and we used the term $\mathrm{Z}$ in Table 3 to avoid confusion. 
Table 3. Ordered Logit Model Estimates

\begin{tabular}{|c|c|c|c|}
\hline+2 & Coefficient & Std. Error & $\mathbf{P}[|\mathbf{Z}|>\mathbf{Z}]$ \\
\hline Constant & 3.6443 & 0.2964 & 0.0000 \\
\hline GPA & 0.0004 & 0.0004 & 0.2281 \\
\hline Gender $1=$ Female, $0=$ Male & 0.3305 & 0.1473 & 0.0249 \\
\hline Age & 0.0002 & 0.0004 & 0.6914 \\
\hline Course $1=$ Macro, $0=$ Micro & 0.3797 & 0.1898 & 0.0454 \\
\hline University housing: $1=\mathrm{Yes}, 0=\mathrm{No}$ & 0.0005 & 0.0007 & 0.5012 \\
\hline$\#$ of hours per week worked at a job & -0.0003 & 0.0001 & 0.0310 \\
\hline Number of mathematics courses taken & 0.0005 & 0.0004 & 0.2022 \\
\hline Number of Economics courses taken & 0.0005 & 0.0003 & 0.0770 \\
\hline SAT Score & 0.0003 & 0.0001 & 0.0005 \\
\hline Expected Grade at the beginning of the semester & -0.0005 & 0.0009 & 0.5868 \\
\hline Expected Grade at the end of the semester & 0.0008 & 0.0006 & 0.1695 \\
\hline \# of hours per week spent on studying for the class & -0.0004 & 0.0004 & 0.3592 \\
\hline Number of missed classes & -0.0019 & 0.0005 & 0.0003 \\
\hline Textbook rating & -0.0003 & 0.0011 & 0.7553 \\
\hline Understanding when the instructor uses graphs to explain a topic & 0.0005 & 0.0014 & 0.7431 \\
\hline Understanding when the instructor uses equations to explain a topic & -0.0007 & 0.0011 & 0.5445 \\
\hline Interest in the course & -0.0026 & 0.0014 & 0.0670 \\
\hline Whether to recommend the course & 0.0013 & 0.0005 & 0.0066 \\
\hline University & 0.0924 & 0.3922 & 0.8137 \\
\hline If Instructor $1=1,0=$ Otherwise & -0.5125 & 0.3390 & 0.1306 \\
\hline If Instructor $2=1,0=$ Otherwise & -0.4077 & 0.6382 & 0.5229 \\
\hline If Instructor $3=1,0=$ Otherwise & -0.6704 & 0.4881 & 0.1696 \\
\hline If Instructor $4=1,0=$ Otherwise & 0.0800 & 0.4697 & 0.8647 \\
\hline If Instructor $5=1,0=$ Otherwise & -0.7418 & 0.5340 & 0.1648 \\
\hline If Instructor $6=1,0=$ Otherwise & -0.8432 & 0.3224 & 0.0089 \\
\hline If Instructor $7=1,0=$ Otherwise & -1.0306 & 0.6422 & 0.1085 \\
\hline If Instructor $8=1,0=$ Otherwise & 0.1801 & 0.5503 & 0.7434 \\
\hline Sophomore $=1,0=$ Otherwise & -0.0278 & 0.1673 & 0.8679 \\
\hline Junior $=1,0=$ Otherwise & 0.4720 & 0.2212 & 0.0328 \\
\hline Senior $=1,0=$ Otherwise & 0.3663 & 0.3570 & 0.3049 \\
\hline Reason for registration: Conflict w/ course & -0.1328 & 0.1789 & 0.4577 \\
\hline Reason for registration: Conflict w/ work & -0.6161 & 0.4120 & 0.1348 \\
\hline Reason for registration: Conflict w/ personal affairs & -0.5819 & 0.4413 & 0.1873 \\
\hline Reason for registration: reputation of instructor & 0.0357 & 0.2289 & 0.8759 \\
\hline $\mathrm{Mu}(1)$ & 1.8699 & 0.1075 & 0.0000 \\
\hline $\mathrm{Mu}(2)$ & 3.6981 & 0.0809 & 0.0000 \\
\hline $\mathrm{Mu}(3)$ & 5.3679 & 0.0976 & 0.0000 \\
\hline \multicolumn{4}{|l|}{ Dependent Variable: Grades } \\
\hline Log likelihood function $=-978.1016$ & \multicolumn{3}{|c|}{ Restricted log likelihood $=-1030.485$} \\
\hline$\chi^{2}=104.7664$ & \multicolumn{3}{|c|}{ Degrees of freedom $=34$} \\
\hline
\end{tabular}

Seven variables are statistically significant at the $5 \%$ level, including gender, course (macro vs. micro), the number of hours worked, SAT score, the number of missed classes, whether or not to recommend the course, and instructor six. In addition, the estimated coefficients for number of economics courses taken and interest in the course are statistically significant at ten percent level.

The interpretation of the estimated coefficients of ordered logit model is not as straightforward as ordinary least square estimates. A coefficient estimate indicates a change in the log of the odds ratio. We first transform the coefficient by using the exponential function to find the antilog $\left(\mathrm{e}^{\beta}\right)$, and then we use the value computed from the transformation to predict the odds ratio. Since we estimate the coefficient for gender as .3305, this yields 1.39 as the odds ratio. This result implies that female students are 1.39 times more likely to get a better grade compared to male students. Likewise, the odds ratio for being a junior, a macroeconomics student, a senior, and registering because of the reputation of the instructor are $1.6,1.5,1.4$, and 1.04 , respectively. 
Table 4: Marginal Effects for Ordered Logit Model

\begin{tabular}{|c|c|c|c|c|c|}
\hline Variables & $\mathbf{F}$ & D & $\mathbf{C}$ & B & $\mathbf{A}$ \\
\hline Constant & 0.0000 & 0.0000 & 0.0000 & 0.0000 & 0.0000 \\
\hline GPA & 0.0000 & 0.0000 & -0.0001 & 0.0000 & 0.0001 \\
\hline Gender $1=$ Female, $0=$ Male & -0.0051 & -0.0230 & -0.0504 & 0.0207 & 0.0579 \\
\hline Age & 0.0000 & 0.0000 & 0.0000 & 0.0000 & 0.0000 \\
\hline Course 1=Macro, $0=$ Micro & -0.0059 & -0.0263 & -0.0579 & 0.0233 & 0.0668 \\
\hline University housing: $1=\mathrm{Yes}, 0=\mathrm{No}$ & 0.0000 & 0.0000 & -0.0001 & 0.0000 & 0.0001 \\
\hline \# of hours per week worked at a job & 0.0000 & 0.0000 & 0.0000 & 0.0000 & -0.0001 \\
\hline Number of mathematics courses taken & 0.0000 & 0.0000 & -0.0001 & 0.0000 & 0.0001 \\
\hline Number of Economics courses taken & 0.0000 & 0.0000 & -0.0001 & 0.0000 & 0.0001 \\
\hline SAT Score & 0.0000 & 0.0000 & 0.0000 & 0.0000 & 0.0001 \\
\hline Expected Grade at the beginning of the semester & 0.0000 & 0.0000 & 0.0001 & 0.0000 & -0.0001 \\
\hline Expected Grade at the end of the semester & 0.0000 & -0.0001 & -0.0001 & 0.0001 & 0.0001 \\
\hline \# of hours per week spent on studying for the class & 0.0000 & 0.0000 & 0.0001 & 0.0000 & -0.0001 \\
\hline Number of missed classes & 0.0000 & -0.0001 & -0.0003 & 0.0001 & 0.0003 \\
\hline Textbook rating & 0.0000 & 0.0000 & 0.0001 & 0.0000 & -0.0001 \\
\hline Understanding when the instructor uses graphs to explain a topic & 0.0000 & 0.0000 & -0.0001 & 0.0000 & 0.0001 \\
\hline Understanding when the instructor uses equations to explain a topic & 0.0000 & 0.0000 & 0.0001 & 0.0000 & -0.0001 \\
\hline Interest in the course & 0.0000 & 0.0002 & 0.0004 & -0.0002 & -0.0005 \\
\hline Whether to recommend the course & 0.0000 & -0.0001 & -0.0002 & 0.0001 & 0.0002 \\
\hline University & -0.0015 & -0.0067 & -0.0141 & 0.0065 & 0.0157 \\
\hline If Instructor $1=1,0=$ Otherwise & 0.0101 & 0.0428 & 0.0733 & -0.0483 & -0.0779 \\
\hline If Instructor $2=1,0=$ Otherwise & 0.0079 & 0.0336 & 0.0590 & -0.0377 & -0.0627 \\
\hline If Instructor $3=1,0=$ Otherwise & 0.0135 & 0.0569 & 0.0943 & -0.0639 & -0.1009 \\
\hline If Instructor $4=1,0=$ Otherwise & -0.0013 & -0.0056 & -0.0122 & 0.0052 & 0.0139 \\
\hline If Instructor $5=1,0=$ Otherwise & 0.0161 & 0.0661 & 0.1006 & -0.0760 & -0.1068 \\
\hline If Instructor $6=1,0=$ Otherwise & 0.0190 & 0.0772 & 0.1113 & -0.0888 & -0.1187 \\
\hline If Instructor $7=1,0=$ Otherwise & 0.0268 & 0.1033 & 0.1218 & -0.1191 & -0.1327 \\
\hline If Instructor $8=1,0=$ Otherwise & -0.0027 & -0.0121 & -0.0277 & 0.0102 & 0.0323 \\
\hline Sophomore $=1,0=$ Otherwise & 0.0004 & 0.0020 & 0.0042 & -0.0019 & -0.0048 \\
\hline Junior $=1,0=$ Otherwise & -0.0066 & -0.0300 & -0.0723 & 0.0211 & 0.0878 \\
\hline Senior $=1,0=$ Otherwise & -0.0050 & -0.0231 & -0.0563 & 0.0159 & 0.0685 \\
\hline Reason for registration: Conflict w/ course & 0.0022 & 0.0098 & 0.0201 & -0.0098 & -0.0223 \\
\hline Reason for registration: Conflict w/ work & 0.0131 & 0.0544 & 0.0848 & -0.0629 & -0.0893 \\
\hline Reason for registration: Conflict w/ personal affairs & 0.0123 & 0.0512 & 0.0804 & -0.0593 & -0.0846 \\
\hline Reason for registration: reputation of instructor & -0.0006 & -0.0025 & -0.0055 & 0.0024 & 0.0062 \\
\hline
\end{tabular}

Table 4 reports the marginal effects of variables on grades. Gender, being in macroeconomics, instructors, being a junior and senior, reason for registering in a certain class due to conflicts with other courses, work, and personal affairs, and reputation of instructor are important variables in learning and success in economics classes. The remaining variables have smaller effects on grades.

\section{CONCLUSIONS}

After investigating class and student attributes on learning in principles of economics classes, we reached to the following conclusions. First, the principles of microeconomics and macroeconomics classes are dominated by male students. Second, unlike the previous studies, which generally found that male students did better in economics classes, our result led to the opposite conclusion. There is a changing pattern of gender effect in the economics classes where female students seem to be doing better than male students do. Third, more than half of the students in our survey had a job outside. Forth, several variables, including gender, course (macro vs. micro), \# of hours worked, SAT score, number of missed classes, recommending the course to a friend, instructors, being a junior, number of economics courses taken, and interest in the course, were found to be the significant factors contributing to learning and success as measured by grades in introductory economics classes. Fifth, the variables, GPA, age, staying in university housing, number of mathematics classes taken, instructor's use of graphs to explain 
a topic, being a fourth year student, enrolling for a class because of the reputation of an instructor, had positive effect on students grades though they are not statistically significant. Finally, the effect of the number of hours per week spent on studying for the class was negative.

\section{REFERENCES}

1. Aries, J. J. \& Waller, D. M. 2004. Additional evidence on the relationship between class size and student performance. Journal of Economic Education, pp. 341-329.

2. Ballard, C.L.\& Johnson, M.F. 2004. Basic math skills and performance in an introductory economics class. Journal of Economic Education, pp. 3-23.

3. Ballard, C. \& Johnson, M. 2005. Gender, expectations, and grades in introductory microseconds at a US university. Feminist Economics, 111, pp. 95-122.

4. Becker, W. E.\& Watts, M. 1995. Teaching tools: Teaching methods in undergraduate economics. American Economic Review, 8612, pp. 448-453.

5. Benedict, M. E. \& Hoag, J. 2004. Seating location in large lectures: Are seating preferences or location related lo course performance? Journal of Economic Education, pp. 215-231.

6. Borg, M. O., Mason, P. M., \& Shapiro, S. L. 1989. The case of effort variables in student performance. Journal of Economic Education, 20, pp. 308-313.

7. Borg, M. \& Shapiro, S.L. 1996, Personality type and student performance in principles of economics. Journal of Economic Education, pp. 3-25.

8. Borg, M. O. \& Stranahan, H. 2002. The effect of gender and race on student performance in principles of economics: The importance of personality type. Applied Economics, 34, pp. 589-598.

9. Chan, K. C; Shum, C. \& Wright, D. J. 1997. Class attendance and student performance in principles of finance. Financial Practice and Education, 7, pp. 58-65.

10. Cohn, E., \& Cohn, S. 1994. Graphs and leaning in principles of economics. AEA Paper and Proceedings, pp. 197- 200.

11. Cohn, E, Cohn, S., Hult, R. E., Balch, D.C., \& Bradley, 5.41998. The effects of mathematics background on student learning in principles of economics. Journal of Education for Business, pp. 18-22.

12. Cohn, E., Cohn, S., Balch, D. C.,\& Bradley, J. 2001. Do graphs promote leaning in principles of economics? Journal of Economic Education, pp. 299-310.

13. Cohn, E. Cohn, s, Balch, D.C.\& Bradley, J. 2004. The relation between student attitudes towards graphs and performance in economics. The American Economist, 482, pp. 41-52.

14. Cohn, E. \& Johnson, E. 2006. Class attendance and performance in principles of economics. Education Economics, 142, Pp. 211-233.

15. Colander, D. 2005. What economists teach and what economists do. Journal of Economic Education, pp. 249-260.

16. Didia D. \& Hasnat, B. 1998. The determinants of ptomaine in the university introductory finance course. Financial Practice and Education, 8, pp. 102-107.

17. Durden G. C.\& Ellis, L. V. 1995. The effects of attendance on student learning in principles of economics. AEA Papers and Proceedings, pp. 343-346.

18. Greene, W. H. 2002. Econometric Analysis. $5^{\text {th }}$ Ed. Prentice Hall.

19. Goffe, W. L. \& Sosin, K. 2005. Teaching with technology: May you live in interesting times. Journal of Economic Education, pp. 278-291.

20. Hill, C.D. \& Stegner. 2003. Which students benefit from graphs in a principles of economics class? The American Economist, 472, pp 69-77.

21. Paul, H. 1982. The impact of outside employment on student achievement in macroeconomic principles. Journal of Economic Education, pp. 51-56.

22. Krohn, G. A. \& O’Connor, C. M. 2005. Student effort and performance over the semester. Journal of Economic Education, pp. 3-28.

23. Laband D. N. \& Piette, M. J. 1995. Better Learning from better management: How to improve the principles of economics course. Does who teaches principles of economics matter? AEA Papers and Proceedings, pp. 335-338.

24. Lumsden, K. G. \& Scott, A. 1987. The economics student reexamined: Male-female differences in comprehension, Journal of Economic Education, 18, pp. 365-375. 
25. Marburger, DR. 2001. Absenteeism and undergraduate exam performance. Journal of Economic Education, 322,pp. 99-109.

26. McConnell, C.R. \& Sosin, K. 1984. Some determinants of student attitudes toward large classes. Journal of Economic Education, pp. 181- 190.

27. Park, K. H. \& Kerr, P. M. 1990. Determinants of academic performance: A multinomial logit approach. Journal of Economic Education, 21, pp. 101-111.

28. Robb, R.E. \& Robb, A. L. 1999. Gender and the study of economics: The role of gender of the instructor. Journal of Economic Education, pp. 3-19.

29. Siegfried, J. J. 1979. Male-female differences in economic education: a survey. Journal of Economic Education, 10, pp. 1-11.

30. Vachris, M.A. 1999. Teaching principles of economies without "chalk and talk": The experience of CNU online. Journal of Economic Education, pp. 292-303.

31. Watts, M. \& Bosshardt, W. 1991. How instructors make a difference: Panel data estimates from principles of economics courses. The Review of Economics and Statistics, pp. 336-340.

32. Williams, M. L., Waldauer, C. \& Duggal, V. G. 1992. Cruder differences in economic knowledge: an extension of the analysis. Journal of Economic Education, pp. 219-231.

\section{NOTES}


NOTES 